\title{
CORRELAÇÃO ENTRE O TEOR DE PROTEÍNAS EM GRÃOS DE TRIGO E A QUALIDADE INDUSTRIAL DAS FARINHAS
}

\author{
LUIZ CARLOS GUTKOSKI * \\ OTONI ROSA FILHO ** \\ CASSIANA TROMBETTA ***
}

\begin{abstract}
Estudou-se o efeito da concentração de proteínas do grão de trigo na qualidade industrial das farinhas, bem como o estabelecimento de curvas de calibração mediante espectrofotometria de reflectância no infravermelho proximal (NIR). Amostras de grãos de trigo dos cultivares OR 1 e Rubi foram coletadas em regiões produtoras do sul do Brasil e realizadas análises de umidade, proteína bruta, peso de mil grãos, peso do hectolitro, grau de extração, número de queda, força do glúten $(W)$, tenacidade $(P)$, extensibilidade $(L)$ e relação $P / L$. As farinhas das amostras de trigo do cultivar Rubi mostraram-se superiores quanto às características alveográficas avaliadas em comparação com as farinhas das amostras de trigo do cultivar OR 1. O teor de proteína bruta das amostras de grãos de trigo do cultivar Rubi apresentou correlação com a força geral do glúten $(0,75)$ e relação $P / L(-0,71)$. Os coeficientes de determinação das equações de proteína bruta $(0,99)$ e umidade $(0,95)$, obtidos nas curvas de calibração pelo NIR foram adequados para predizer a concentração dos constituintes químicos avaliados.
\end{abstract}

PALAVRAS-CHAVE: TRIGO; TRIGO-FARINHA; NIR.

\section{INTRODUÇÃO}

A qualidade de grãos e farinhas de cereais é definida por diversas características que assumem diferentes significados dependendo da

* Engenheiro Agrônomo, Doutor em Engenharia de Alimentos, Professor da Faculdade de Agronomia e Medicina Veterinária, Universidade de Passo Fundo (UPF-RS), Bolsista do CNPq. (e-mail: gutkoski@upf.tche.br).

** Engenheiro Agrônomo, Doutor em Melhoramento de Plantas, Pesquisador da OR Melhoramentos, Passo Fundo, RS.

*** Bolsista PIBIC, CNPq, Curso de Ciências - Habilitação em Química, UPF, RS. 
designação de uso ou tipo de produto. Estas características podem ser divididas em físicas, químicas e reológicas $(11,13)$.

A qualidade do grão de trigo pode ser definida como o resultado da interação que a cultura sofre no campo, pelo efeito das condições de solo, do clima, da incidência de pragas e moléstias, do manejo da cultura e tipo de cultivar semeado. Também é influenciada pelas operações de colheita, secagem, armazenamento e de moagem. A avaliação reológica da farinha, na qual são determinadas as propriedades viscoelásticas da massa, é de vital importância para a indústria de panificação permitindo predizer o seu uso final. A reologia também desempenha importante papel no controle de qualidade e na especificação de ingredientes e aditivos a serem utilizados nos produtos elaborados $(9,13)$.

As características reológicas da farinha dependem da quantidade e da qualidade das proteínas presentes no grão de trigo. De acordo com BUSHUK (4), o teor de proteínas do grão de trigo varia em função de fatores agronômicos e ambientais enquanto que a qualidade das proteínas é característica primariamente genotípica. Tal autor obteve correlação positiva entre o teor de proteínas do grão de trigo e o volume do pão produzido. BRANLARD et al. (2) avaliaram parâmetros de qualidade de trigo e encontraram fraca correlação entre o número de queda e a força geral do glúten. Os resultados do teste de número de queda são influenciados por vários fatores como tipo de amostra, teor de umidade, temperatura do banho e tratamento térmico do grão, além do procedimento de agitação (8). Por outro lado, ORTH e MANDER (10) verificaram aumento no teor de proteínas e na absorção de água em farinhas com o aumento da taxa de extração e diminuição da força geral do glúten.

A espectrofotometria de reflectância no infravermelho proximal (NIR) vem apresentando expansão de usos na área de alimentos, cuja técnica baseia-se na utilização de curvas especiais dos materiais analisados. KRISHNAN (7) validou o uso desta técnica para a determinação dos teores de proteínas e de óleos de cultivares de aveia com coeficientes de correlação de 0,98 e 0,99, respectivamente. DELWICHE et al. (6) utilizando amostras de grãos de trigo de trinta genótipos, colhidos em duas safras e de nove locais de plantio, avaliaram o teor de proteínas, sedimentação e propriedades da massa pelo uso do NIR. Os resultados de correlação variaram entre 0,87 e 0,94 evidenciando que os modelos foram suficientemente adequados para predizer a qualidade do trigo. O teor de proteínas modelado pelo uso do NIR apresentou exatidão. 
Pretendeu-se neste trabalho estudar o efeito da concentração de proteínas do grão de trigo na qualidade industrial das farinhas, mediante avaliação da força do glúten $(W)$, tenacidade $(P)$, extensibilidade $(L)$ e relação $P / L$, bem como estabelecer curvas de calibração pelo uso de espectrofotometria de refletância no infravermelho proximal (NIR).

\section{MATERIAL E MÉTODOS}

\subsection{MATERIAL}

Foram utilizadas amostras de grãos de trigo (Triticum aestivum $L$ ) dos cultivares OR 1 (60) e Rubi (20). As sessenta amostras de OR 1 foram coletadas em diversas regiões produtoras do Sul do Brasil, com o objetivo de cobrir integralmente o intervalo de variação de proteínas no grão, possibilitando melhor calibração do espectrofotômetro. As vinte amostras do cultivar Rubi foram obtidas a partir de ensaio experimental realizado no município de Passo Fundo. Foram utilizadas na adubação da cultura diferentes doses de nitrogênio, aplicadas no plantio e na forma de cobertura. As amostras foram analisadas no mínimo em triplicata quanto às características físicas, químicas e reológicas.

\subsection{MÉTODOS}

\section{- Peso de mil grãos}

O peso de mil grãos foi determinado de acordo com a metodologia descrita nas Regras para análise de sementes (3) pela contagem manual de cinqüenta grãos em quadruplicata.

\section{- Peso do hectolitro}

Determinou-se o peso do hectolitro segundo metodologia descrita nas Regras para análise de sementes (3), mediante uso de balança Dalle Molle. Os resultados, após emprego de tabela de conversão foram expressos em $\mathrm{kg} / \mathrm{hL}$.

\section{- Extração de farinha}

A extração de farinha foi realizada de acordo com as instruções do manual do fabricante do moinho piloto (5). As amostras de grãos de trigo foram 
pesadas individualmente, condicionadas para 15\% de umidade e após 24 horas, moídas em moinho de laboratório Chopin, modelo CD1. O rendimento de extração de farinha foi expresso em percentagem com base no peso total dos produtos obtidos.

\section{- Teor de umidade e proteína bruta}

Os conteúdos de umidade e proteína bruta foram determinados de acordo com metodologia proposta pela AACC (1), métodos números 44-15A, e 46-13, respectivamente. Para expressar o valor de proteína bruta utilizouse o fator de conversão 5,7 e os resultados foram corrigidos na base de $14 \%$ de umidade.

\section{- Número de queda}

O número de queda foi determinado pelo aparelho Falling Number, de acordo com o método número 56-81B da AACC (1), utilizando-se sete gramas de farinha, com umidade corrigida para $14 \%$.

\section{- Alveografia}

As características viscoelásticas das amostras de farinha de trigo foram determinadas em alveógrafo Chopin pelo método $n^{\circ}$ 54-30 da AACC (1). Os parâmetros utilizados para a análise dos alveogramas foram $\mathrm{P}$ ou tenacidade $(\mathrm{mm})$, L ou elasticidade $(\mathrm{mm})$ e W ou energia de deformação, que corresponde ao trabalho mecânico necessário para deformar a massa até a ruptura. Com a área da curva em centímetros quadrados multiplicada pela constante do aparelho $(6,54)$ obteve-se o valor de W, que é expresso em $10^{-4} \mathrm{~J}$.

\section{- Curvas de calibração}

Os dados das amostras de cada um dos cultivares, após as análises de umidade e proteína bruta, foram arquivados em software e foi realizada a calibração utilizando-se espectrofotômetro de reflectância no infravermelho proximal (NIR), marca Perstorp Analytical, modelo 5000 (15).

\section{- Análise estatística}

Para avaliar os resultados empregou-se o método de análise estatística univariada. O processamento de dados e a análise estatística foram elaborados com o uso do programa estatístico SAS Institute (14). A 
significância dos modelos foi testada pela Análise de variância (ANOVA) ao nível de $5 \%$ de probabilidade de erro $(p \leq 0,05)$. Para os modelos significativos foram construídas as curvas de regressão, sendo também avaliada a correlação entre todas as variáveis estudadas ao nível de 5\% de probabilidade de erro $(p \leq 0,05)$.

\section{RESULTADOS E DISCUSSÃO}

Nas Tabelas 1 e 2 são apresentadas as correlações entre as determinações físicas, químicas e reológicas realizadas nas amostras de grãos e farinhas dos cultivares de trigo estudados. O teor de proteínas das amostras de grãos de trigo do cultivar OR variou entre 9,89\% e 13,16\%, com média de $11,59 \%$ e desvio padrão de 0,93 , não sendo verificada correlação significativa com as medidas de força geral do glúten (W), tenacidade e relação $P / L$. A variação do teor de proteínas verificada nas amostras do cultivar, que foi colhido em diferentes locais, não foi suficiente para apresentar correlação significativa com análises de qualidade industrial. Provavelmente a variação da porcentagem de proteínas presente nos grãos foi mascarada pelas condições ambientais, como ocorrência de doenças, pluviosidade, temperatura e manejo de lavoura.

\section{TABELA 1 - CORRELAÇÃO ENTRE AS DETERMINAÇÕES FÍSICAS, QUÍMICAS E REOLÓGICAS DE AMOSTRAS DE GRÃOS E DE FARINHAS DO CULTIVAR DE TRIGO OR 1}

\begin{tabular}{lllllll}
\hline Variável & 1 & 2 & 3 & 4 & 5 & 6 \\
\hline 1 Peso mil grãos & $\mathbf{1 , 0 0}$ & & & & & \\
2 Peso do hectolitro & $0,33^{\star}$ & $\mathbf{1 , 0 0}$ & & & & \\
3 Proteínas & $-0,18$ & $-0,36^{\star}$ & $\mathbf{1 , 0 0}$ & & & \\
4 Força do glúten (W) & 0,25 & $0,45^{\star}$ & $-0,13$ & $\mathbf{1 , 0 0}$ & & \\
5 Tenacidade (P) & 0,27 & $0,37^{\star}$ & $-0,13$ & $0,80^{\star}$ & $\mathbf{1 , 0 0}$ & \\
6 Relação P/L & 0,18 & $0,32^{*}$ & $-0,22$ & $0,34^{\star}$ & 0,51 & $\mathbf{1 , 0 0}$ \\
& & & & & & \\
\hline
\end{tabular}

*- correlação significativa ao nível de 5\% de probabilidade de erro.

BRANLARD et al. (2) verificaram que o conteúdo de proteínas correlacionase fortemente com a força geral do glúten, farinografia, teor de glúten e teste de panificação experimental. A relação tenacidade/extensibilidade 
(P/L) determinada na análise de alveografia apresentou fraca correlação com teor de proteínas do grão de trigo.

Em trabalho realizado por ROSA FILHO (12) foi verificado que as amostras de trigo com baixos teores de proteínas (10 a 11\%) apresentaram menores valores de $\mathrm{W}$. Entretanto nas amostras com altos teores de proteína bruta (13 a 14\%) foram observados os maiores valores, chegando a força do glúten a $290 \times 10^{-4} \mathrm{~J}$. Esta relação somente é valida para amostras de um único cultivar, já que estes diferem quanto ao tipo de proteínas sintetizadas no grão. Importante aplicação da correlação entre a força do glúten (W) e a porcentagem de proteínas em cultivar conhecido de trigo é que ao se determinar a porcentagem de proteínas pode-se predizer a força de glúten do trigo. Assim, pode-se separar em lotes, os trigos com alta porcentagem de proteínas (alto W) e com baixa porcentagem de proteínas (baixo W). Porém este não foi o comportamento verificado nas amostras de trigo do cultivar OR 1. A baixa variação na concentração de proteínas entre as amostras analisadas também pode justificar a não observância de correlação entre teor de proteínas e a qualidade industrial avaliada principalmente pelo $\mathrm{W}$.

\section{TABELA 2 - CORRELAÇÃO ENTRE AS DETERMINAÇÕES FÍSICAS, QUÍMICAS E REOLÓGICAS DE AMOSTRAS DE GRÃOS E DE FARINHAS DO CULTIVAR DE TRIGO RUBI}

\begin{tabular}{lllllll}
\hline Variável & 1 & 2 & 3 & 4 & 5 & 6 \\
\hline 1 Peso mil grãos & $\mathbf{1 , 0 0}$ & & & & & \\
2 Peso do hectolitro & 0,13 & $\mathbf{1 , 0 0}$ & & & & \\
3 Proteínas & $0,54^{\star}$ & $-0,21$ & $\mathbf{1 , 0 0}$ & & & \\
4 Força do glúten (W) & 0,31 & $-0,04$ & $0,75^{\star}$ & $\mathbf{1 , 0 0}$ & & \\
5 Tenacidade (P) & $-0,36$ & 0,32 & $-0,37$ & $-0,08$ & $\mathbf{1 , 0 0}$ & \\
6 Relação P/L & $-0,52^{\star}$ & 0,33 & $-0,71^{\star}$ & $-0,74^{\star}$ & $0,51^{\star}$ & $\mathbf{1 , 0 0}$ \\
\hline
\end{tabular}

*- correlação significativa ao nível de $5 \%$ de probabilidade de erro.

Nas amostras do cultivar de trigo Rubi o teor de proteínas variou entre $10,09 \%$ e 14,00\%, com média de 12,24 e desvio padrão de 1,02. Observouse para este cultivar maior variação no teor de proteínas, conforme mostrado pelo desvio padrão em comparação com os dados do cultivar OR 1. As amostras de trigo do cultivar Rubi apresentaram forte correlação entre a concentração de proteínas do grão e a qualidade industrial das 
farinhas, verificada pela força geral do glúten $(0,75)$ e relação $P / L(-0,71)$. As amostras do cultivar Rubi, diferentemente do ocorrido para OR 1, foram obtidas a partir de único local de cultivo, sendo variada a quantidade de nitrogênio utilizada na adubação de base e de cobertura. Os resultados de correlação obtidos para o experimento, realizado com as amostras de trigo do cultivar Rubi, apresentaram-se similares aos obtidos por ROSA FILHO (12).

Pode-se observar pela Figura 1 que a força geral do glúten das farinhas do cultivar Rubi elevou-se com o aumento na concentração de proteínas do grão, embora o coeficiente de determinação da equação linear obtida explique apenas 0,58 da variação total. Já para o cultivar OR 1, este comportamento não foi observado e o coeficiente de determinação obtido na equação de regressão foi de 0,02.

\section{FIGURA 1 - REGRESSÃO LINEAR ENTRE A FORÇA GERAL DO GLÚTEN E O TEOR DE PROTEÍNAS PARA AMOSTRAS DOS CULTIVARES DE TRIGO OR 1 E RUBI}

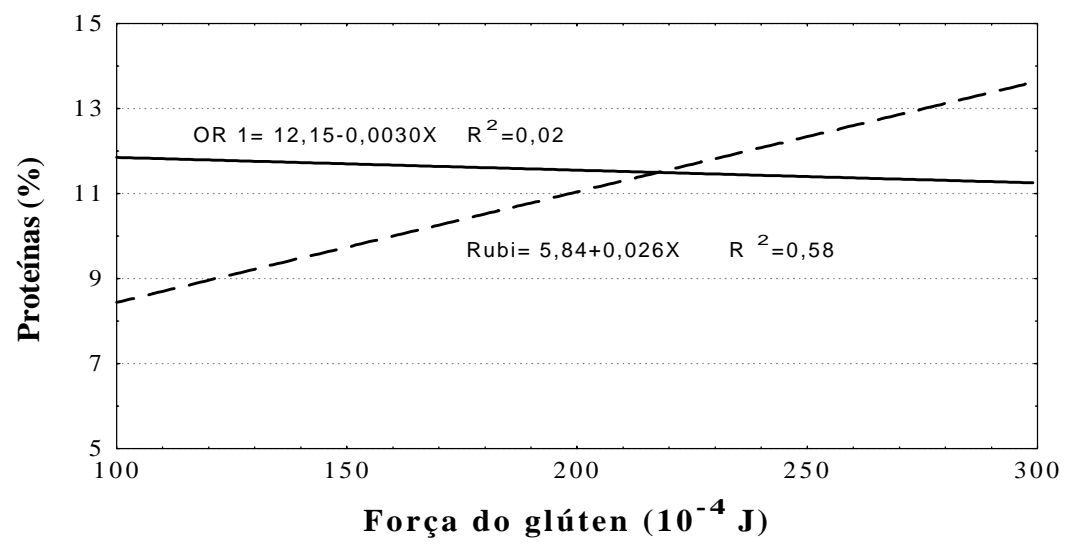

A relação $\mathrm{P} / \mathrm{L}$, da farinha de trigo do cultivar Rubi, apresentou comportamento inversamente proporcional ao teor de proteínas do grão de trigo e o coeficiente de determinação obtido na equação de regressão, foi de 0,52. Assim, com a elevação no teor de proteínas do grão ocorreu aumento da tenacidade $(P)$ e diminuição da extensibilidade (L), 
ocasionando menor relação P/L (Figura 2). Novamente este fato não foi verificado para o experimento realizado com o cultivar de trigo OR 1 e o coeficiente de determinação, obtido na equação de regressão, foi de apenas 0,06 .

\section{FIGURA 2 - REGRESSÃO LINEAR ENTRE A RELAÇÃO P/L E O TEOR DE PROTEÍNAS PARA AMOSTRAS DOS CULTIVARES DE TRIGO OR 1 E RUBI}

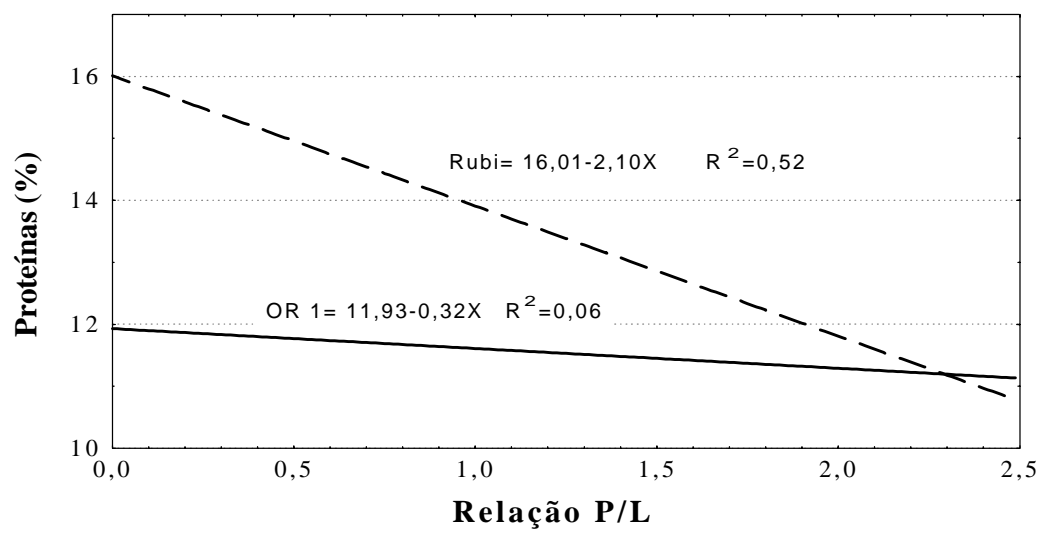

Os resultados evidenciaram que grãos do mesmo cultivar de trigo plantados em condições edafoclimáticas similares podem ser analisados a partir da concentração de proteínas nos grãos, visando predizer a qualidade industrial da farinha. Novos trabalhos devem ser realizados quando ocorrer variação nos locais de cultivo.

As equações de regressão linear e os respectivos coeficientes de determinação, obtidos a partir da análise por espectrofotometria de reflectância no infravermelho proximal para umidade $(0,95)$ e proteínas $(0,99)$, estão representados nas Figuras 3 e 4 . Esses resultados estão de acordo com os dados obtidos por KRISHNAN (7), indicando a possibilidade do uso do NIR para a determinação de proteínas e umidade em trigo a partir de 80 amostras utilizadas na construção das equações de regressão. 
FIGURA 3 - GRÁFICO DA REGRESSÃO LINEAR ENTRE UMIDADE, OBTIDA PELO MÉTODO DA AACC E PELO NIR, PARA AMOSTRAS DOS CULTIVARES DE TRIGO OR 1 E RUBI

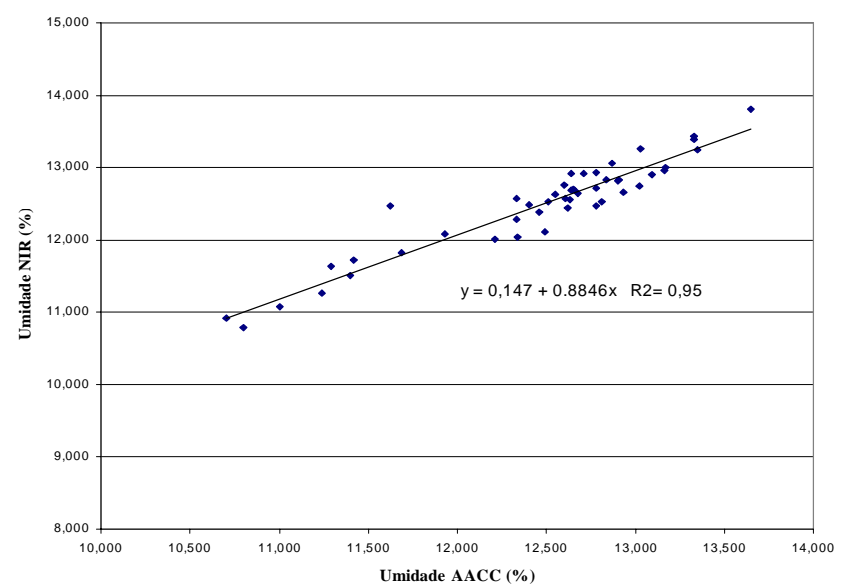

FIGURA 4 - GRÁFICO DA REGRESSÃO LINEAR ENTRE A PROTEÍNA BRUTA, OBTIDA PELO MÉTODO AACC E PELO NIR, PARA AMOSTRAS DO CULTIVAR DE TRIGO OR 1

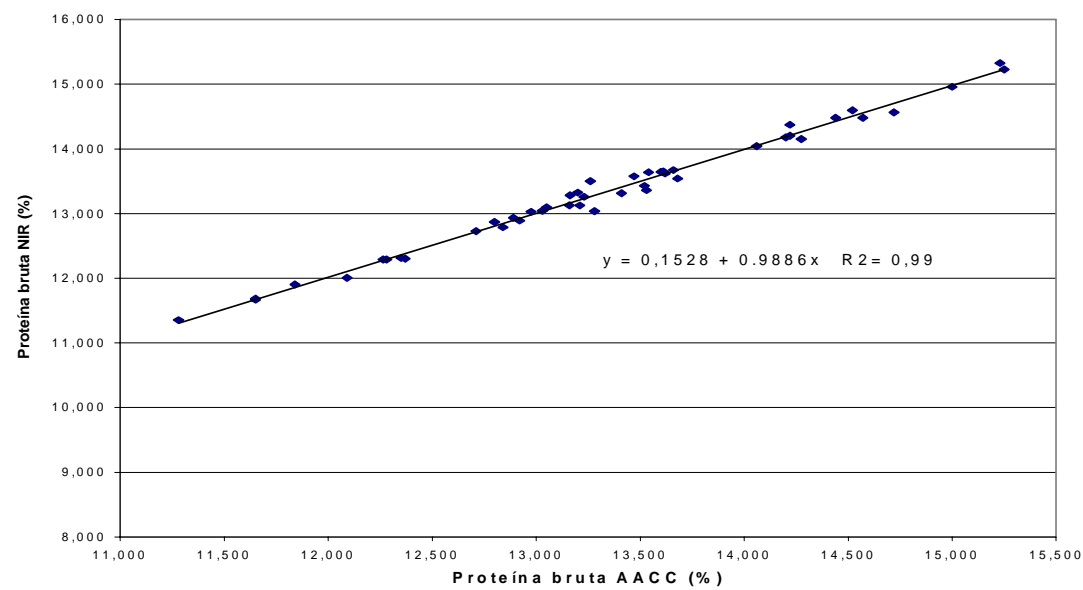




\section{CONCLUSÃO}

Os dados experimentais do presente trabalho permitem concluir que as amostras do cultivar Rubi mostraram-se superiores quanto às características físicas, químicas e reológicas, em comparação com as amostras de trigo do cultivar OR 1.

Foram verificadas correlações entre o teor de proteínas e a força geral do glúten $(0,75)$ e sua relação $P / L(-0,71)$ no cultivar Rubi.

Os coeficientes de determinação das equações de proteínas $(0,99)$ e de umidade $(0,95)$ indicam que as curvas de calibração obtidas pelo NIR foram adequadas para predizer a concentração dos constituintes químicos avaliados.

\section{Abstract \\ CORRELATION BETWEEN PROTEIN CONTENT IN WHEAT GRAINS AND THE INDUSTRIAL QUALITY OF FLOURS}

The protein content of wheat grain in the industrial quality of flours was studied, as well as the development of calibration curves by NIR. Samples of wheat cultivars OR-1 and Rubi were collected in several regions and the analysis of moisture, protein content, thousand grain weight, hectoliter weight, flour extraction grade, falling number and alveography were undertaken. The wheat flour samples of the Rubi cultivar were superior for the alveography characteristics evaluated in comparison with the wheat samples of cultivar OR1. The protein content of wheat samples cultivar Rubi showed correlation with dough strength $(0,75)$ and $P / L$ ratio $(-0,71)$. The determination coefficients for protein $(0,99)$ and moisture $(0,95)$ equations were adequate to predict the concentration of the chemical constituents evaluated.

KEY WORDS: WHEAT; FLOUR; NIR.

\section{REFERÊNCIAS}

1 AACC. American Association of Cereal Chemists. Approved methods. 9 $9^{\text {th }}$ ed. Saint Paul, 1995.

2 BRANLARD, G.; ROUSSET, M.; LOISEL, W.; AUSTRAN J.C. Comparison of 46 technological parameters used in breeding for bread wheat quality evaluation. Journal Genetic \& Breeding, v.45, n 4, p.263-280, 1991. 
3 BRASIL. Ministério da Agricultura e Reforma Agrária. Secretaria Nacional de Defesa Agropecuária. Regras para análise de sementes. Brasília, 1992. 365 p.

4 BUSHUK, W. Flour proteins: structure and functionality in dough and bread. Cereal Foods World, v.30, n.7, p.447-451, 1985.

5 CHOPIN. Instruction manual of laboratory mill (CD1). VilleneuveLa-Garenne: Chopin, 1999.

6 DELWICHE, S. R.; GRAYBOSCH, R.A.; PETERSON, C.J. Predicting protein composition, biochemical properties, and dough-handling properties of hard red winter wheat flour by near-infrared reflectance. Cereal Chemistry, v.75, n.4, p.412-416, 1998.

7 KRISHNAN, P.G. Measurement of protein and oil content of oat cultivars using near-infrared reflectance spectroscopy. Cereal Foods World, v.39, n.2, p.105-108, 1994.

8 PERTEN, H. Factors influencing falling number values. Cereal Science Today, v.12, n.12, p. 516-519, 1967.

9 POMERANZ, Y. Modern cereal science and technology. New York: VHC Publishers, 1987. $486 \mathrm{p}$.

10 ORTH, R.A.; MANDER, K.C. Effect of milling yield on flour composition and breadmaking quality. Cereal Chemistry, v.52, n.3, p.305-314, 1975.

11 RASPER, V.F. Quality evaluation of cereal and cereal products. In: LORENZ, K.J.; KULP, K. (Ed.). Handbook of cereal science and technology. New York: Marcel Dekker, 1991. p. 595-638.

12 ROSA FILHO, O. Uso de adubação nitrogenada no espigamento para melhorar a qualidade industrial do trigo. Passo Fundo: Aldeia, 1999. (Comunicado Técnico no 1 da OR Melhoramento de Sementes Ltda.).

13 RAO G. V.;RAO P.H. Methods for determining rheological characteristics of doughs: a critical evaluation. Journal of Food Science Technology, v.30, n.2, p.77-87, 1993. 
14 SAS INSTITUTE. Statistical Analysis System. User's guide: statistics. $5^{\text {th }}$ ed. Cary, 1985. 956p.

15 SHENK, J.S.; WESTERHAUS, M.O. Analysis of agriculture and food products by near infrared reflectance spectroscopy. Madison: NIRSystems, 1995. 124p.

\section{Agradecimentos}

À Fundação de Amparo a Pesquisa do Estado do Rio Grande do Sul - Fapergs, pelo auxílio financeiro ao projeto, processo 97/1411.0. Ao Eng. Agrônomo, MS. Roberto Serena Fontaneli, responsável pelo Laboratório NIR do Cepa/UPF, pelas análises realizadas no equipamento Perstorp Analytical, modelo 5000. 